\title{
Target-achieved propofol concentration during on-pump cardiac surgery: a pilot dose-finding study
}

\section{Concentration cible de propofol atteinte pendant une chirurgie cardiaque avec circulation extra-corporelle: une étude pilote de détermination de dose}

\author{
Koen Raedschelders, BSc · Yu Hui, MSc · Bradley Laferlita, MBBS · \\ Tao Luo, MD, PhD · Hong Zhang, PhD · David D. Y. Chen, PhD • \\ David M. Ansley, MD
}

Received: 17 November 2008/Revised: 28 May 2009/ Accepted: 8 June 2009

(C) Canadian Anesthesiologists' Society 2009

\begin{abstract}
Purpose Propofol concentrations that produce laboratory-based cardioprotective effects are generally greater than those produced under routine anesthesia during cardiac surgery. It is unknown whether experimental cardioprotective propofol concentrations can routinely be achieved during cardiopulmonary bypass (CPB) using continuous infusion.

Methods Twenty-four patients scheduled for primary aortocoronary bypass grafting with CPB were allocated to receive one of three propofol infusion rates; 50, 100, or $150 \mu \mathrm{g} \cdot \mathrm{kg}^{-1} \cdot \mathrm{min}^{-1}$ in an open-label pilot study. Data were described using a line of best fit to derive an experimental clinical maneuver predicted to produce a whole blood concentration of $5 \mu \mathrm{g} \cdot \mathrm{mL}^{-1}$ at reperfusion. A predetermined interim analysis of 30 patients who were receiving the derived maneuver in an ongoing study was used to evaluate the maneuver. Cardiac index (CI),
\end{abstract}

K. Raedschelders, BSc $\cdot$ B. Laferlita, MBBS

T. Luo, MD, PhD - D. M. Ansley, MD ( $\square)$

Department of Anesthesiology, Pharmacology, and

Therapeutics, The University of British Columbia,

Rm 3200 3rd Floor, JPP. 910 West 10th Ave, Vancouver,

BC V5Z 4E3, Canada

e-mail: david.ansley@vch.ca

Y. Hui, MSc · H. Zhang, PhD - D. D. Y. Chen, PhD Department of Chemistry, The University of British Columbia,

Vancouver, BC V5Z 4E3, Canada systemic vascular resistance index (SVRI), and left ventricular stroke work index (LVSWI) were recorded.

Results The infusion rate-concentration curve had an equation of $y=0.215 e^{0.0279 x}$, where y represents the whole blood concentration and $x$ represents the infusion rate $\left(r^{2}=0.781\right)$. The predicted infusion rate to achieve a mean concentration of $5 \mu \mathrm{g} \cdot \mathrm{mL}^{-1}$ was $113 \mu \mathrm{g} \cdot \mathrm{kg}^{-1} \cdot \mathrm{min}^{-1}$. The nearest practical rate is $120 \mu \mathrm{g} \cdot \mathrm{kg}^{-1} \cdot \mathrm{min}^{-1}$, producing a concentration of $5.39(1.45) \mu \mathrm{g} \cdot \mathrm{mL}^{-1}$. The values for CI, SVRI, and LVSWI were similar between groups at corresponding time periods.

Conclusions An infusion rate of $120 \mu \mathrm{g} \cdot \mathrm{kg}^{-1} \cdot \mathrm{min}^{-1}$ is clinically practical and capable of achieving experimental cardioprotective propofol concentrations at reperfusion.

\footnotetext{
Résumé

Objectif Les concentrations de propofol qui provoquent des effets cardioprotecteurs lors des tests de laboratoire sont en général plus élevées que celles produites sous une anesthésie de routine lors d'une chirurgie cardiaque. Nous ne savons pas si des concentrations expérimentales cardioprotectrices de propofol peuvent être atteintes de façon routinière pendant la circulation extracorporelle (CEC) avec une perfusion continue.

Méthode Vingt-quatre patients devant subir un pontage aortocoronarien avec CEC ont été randomisés à recevoir l'un des trois vitesses de perfusion de propofol suivantes: 50, 100 ou $150 \mu \mathrm{g} \cdot \mathrm{kg}^{-1} \cdot \mathrm{min}^{-1}$ dans une étude pilote ouverte. Les données ont été décrites à l'aide d'une droite de régression afin de dériver une manœuvre clinique expérimentale qui devrait produire une concentration de sang total de $5 \mu \mathrm{g} \cdot \mathrm{mL}^{-1}$ au moment de la reperfusion. Une
} 
analyse intérimaire prédéterminée de 30 patients recevant la manœuvre dérivée dans une étude en cours a été utilisée pour évaluer la manceuvre. L'index cardiaque (IC), l'index de résistance vasculaire systémique (SVRI) et l'index de travail ventriculaire gauche (LVSWI) ont été enregistrés.

Résultats La courbe taux de perfusion - concentration a eu une équation de $y=0,215 e^{0,0279 x}$, où y représente la concentration de sang total et $x$ la vitesse de perfusion $\left(r^{2}=0,781\right)$. La vitesse de perfusion prédite afin d'atteindre une concentration moyenne de $5 \mu \mathrm{g} \cdot \mathrm{mL}^{-1}$ était de $113 \mu \mathrm{g} \cdot \mathrm{kg}^{-1} \cdot \mathrm{min}^{-1}$. La vitesse pratique la plus proche est $120 \mu \mathrm{g} \cdot \mathrm{kg}^{-1} \cdot \mathrm{min}^{-1}$, ce qui produit une concentration de $5.39(1,45) \mu g \cdot m L^{-1}$. Les valeurs de IC, SVRI et LVSWI étaient comparables entre les groupes aux périodes de temps correspondantes.

Conclusion Une vitesse de perfusion de propofol de $120 \mu \mathrm{g} \cdot \mathrm{kg}^{-1} \cdot \mathrm{min}^{-1}$ est pratique d'un point de vue clinique et peut atteindre des concentrations expérimentales cardioprotectrices au moment de la reperfusion.

Ischemia reperfusion injury during aortocoronary bypass grafting (ACBP) is a source of intraoperative cardiac injury. ${ }^{1}$ Therapeutic pharmacologic options to preserve the viability of ischemic myocardium during surgery include volatile anesthetic pre- and post-conditioning and antioxidant therapies. ${ }^{2-5}$ Unfortunately, the clinical reproducibility and effectiveness of volatile anesthetic preconditioning have recently come into question. ${ }^{6,7}$ Preconditioning has not translated easily to the clinical scenario and is not universally effective. Patient factors, including diabetic status ${ }^{8,9}$ and aortic cross-clamp intervals exceeding 30 to $40 \mathrm{~min},{ }^{10}$ could mitigate the effects of the preconditioning stimulus. Research into alternative approaches of cardioprotection is required.

Conditions at reperfusion significantly contribute to tissue injury and repair. ${ }^{11}$ The antioxidant ${ }^{12}$ and cell signalling properties ${ }^{13,14}$ of propofol, as well as its ability to inhibit mitochondrial permeability transition, ${ }^{15,16}$ are well suited to reduce reperfusion injury. Unfortunately, clinical anesthetic conditioning studies have demonstrated that target-controlled infusions of propofol that were set from 1 to $4 \mu \mathrm{g} \cdot \mathrm{mL}^{-1}$ failed to protect against myocardial injury. ${ }^{2,17}$ Based on work from our lab and others using both simulated models of ischemia reperfusion and studies in patients, ${ }^{18-25}$ we postulated that propofol confers cardioprotection when a target range of $4.5-8.9 \mu \mathrm{g} \cdot \mathrm{mL}^{-1}$ ( 25 to $50 \mathrm{mM}$ ) is achieved.

There has been limited in vivo study evaluating the effect of increased propofol dosing to achieve the therapeutic concentration range defined in vitro. Recently, a clinically relevant swine model of normothermic blood cardioplegic arrest with cardiopulmonary bypass (CPB) demonstrated that a $1 \mathrm{mg} \cdot \mathrm{kg}^{-1}$ bolus followed by a $100 \mu \mathrm{g} \cdot \mathrm{kg}^{-1} \cdot \mathrm{min}^{-1}$ continuous propofol infusion was cardioprotective without negative hemodynamic consequences. ${ }^{24}$ The authors estimated a whole-blood propofol concentration of $3.7 \mu \mathrm{g} \cdot \mathrm{mL}^{-1}$ based on other clinical studies with similar operative procedures. ${ }^{26-28} \mathrm{We}$ previously found that a 2 to $2.5 \mathrm{mg} \cdot \mathrm{kg}^{-1}$ bolus of propofol followed by an infusion of $200 \mu \mathrm{g} \cdot \mathrm{kg}^{-1} \cdot \mathrm{min}^{-1}$ produced drug concentrations associated with increased antioxidant capacity $\left(8.2 \pm 2.1 \mu \mathrm{g} \cdot \mathrm{mL}^{-1}\right)$ but showed signs of intraoperative cardiac depression compared with conventional propofol or isoflurane anesthesia maintenance. ${ }^{29}$ More recently, increasing propofol anesthetic maintenance from 60 to $120 \mu \mathrm{g} \cdot \mathrm{kg}^{-1} \cdot \mathrm{min}^{-1}$ intraoperatively was associated with a reduction in biomarkers of cardiac injury and oxidative stress, although the range of values was consistent with those expected during cardiac surgery. ${ }^{30}$ Clinically relevant differences in hemodynamic variables and left ventricular function were not detected in this study, and drug concentrations were not measured. Further investigations are needed to evaluate the role of propofol in cardiac surgery.

It is unknown if experimental cardioprotective propofol concentrations can routinely be achieved at reperfusion during ACBP with CPB using short-term continuous infusion, or if such concentrations are associated with an increased risk of cardiac instability upon emergence from CPB. To address this question, we conducted a pilot dosefinding study to develop predictive mathematical modelling for optimal dosing in patients.

In this pilot study, we hypothesized that a whole-blood propofol concentration of $5 \mu \mathrm{g} \cdot \mathrm{mL}^{-1}$ could be achieved clinically with continuous drug delivery during ACBP with $\mathrm{CPB}$. We focused our treatment interval to the CPB interval of ACBP and measured the resulting propofol concentrations in whole blood $15 \mathrm{~min}$ after reperfusion. We also sought to identify any evidence of clinically significant cardiac depression upon separation from bypass and measured intraoperative hemodynamic performance using cardiac index (CI), systemic vascular resistance index (SVRI), and left ventricular stroke work index (LVSWI).

\section{Methods}

Study design

We report on two successive studies with the aim of establishing a clinical anesthetic maneuver that reliably yields a target concentration of $5 \mu \mathrm{g} \cdot \mathrm{mL}^{-1}$.

The first study (Study 1) was an open-label pilot dosefinding study in 24 patients who received one of three propofol doses by continuous infusion during CPB. 
Propofol concentrations were mathematically described as a function of the infusion rate with an empirical line of best fit constructed using nonlinear regression followed by Akaike's Information Criteria comparison. The line was not modelled on pharmacokinetic or physiological principles. We used this line to determine the infusion rate predicted to yield our target propofol concentration.

The infusion rate derived from Study 1 was employed in a subsequent and ongoing randomized controlled trial entitled PRO-TECT II (www.clinicaltrials.gov NCT00734383). ${ }^{31}$ We planned an analysis of propofol concentrations at the midpoint of the PRO-TECT II trial $(n=72)$ in those patients randomized to the propofol treatment arm $(n=30)$. The purpose of this interim analysis (Study 2) was to assess the reliability with which our clinical maneuver achieved our target propofol concentration at reperfusion.

Both studies focused on propofol concentrations in whole blood sampled $15 \mathrm{~min}$ after reperfusion, which precluded pharmacokinetic analysis. Intraoperative hemodynamic measures of CI, SVRI, and LVSWI were also recorded in both studies.

\section{Study population}

This investigation conforms to the principles outlined in the Declaration of Helsinki. Following institutional approval and informed patient consent, we enrolled hemodynamically stable patients scheduled for revascularization of three or more coronary vessels where a minimum continuous aortic cross-clamp time of $60 \mathrm{~min}$ was anticipated. We excluded patients who were younger than 18 or older than $80 \mathrm{yr}$ of age, those who refused consent, and those who had co-existing valvular heart disease, an acute or evolving myocardial infarction, or a history of hypersensitivity to propofol or any formulation component.

\section{Perioperative procedures}

Perioperative monitoring (arterial, central, and pulmonary catheterization) and surgical and cardioplegia techniques (warm, intermittent, antegrade delivery of blood: crystalloid [8:1 ratio]) were standardized. The antifibrinolytic therapy of choice was tranexamic acid $0.05 \mathrm{mg} \cdot \mathrm{kg}^{-1}$ then $0.10 \mu \mathrm{g} \cdot \mathrm{kg}^{-1} \cdot \mathrm{min}^{-1}$. Cardiopulmonary bypass was conducted at $34-37^{\circ} \mathrm{C}$. Intraoperative hematocrit was maintained at 0.25 to 0.27 during $\mathrm{CPB}$ and facilitated by retrograde autologous prime procedure.

\section{Anesthesia protocol}

Anesthesia was standardized to induction with fentanyl $10-15 \mu \mathrm{g} \cdot \mathrm{kg}^{-1} i v$, midazolam $2-4 \mathrm{mg} i v$, and sodium thiopental, as required for loss of consciousness. Muscle relaxation and tracheal intubation were achieved with rocuronium $0.1 \mathrm{mg} \cdot \mathrm{kg}^{-1}$. Anesthesia was maintained with isoflurane (0.5-2\%, end-tidal), except during CPB when propofol was administered. Post-CPB anesthesia was as per clinical practice.

Experimental maneuver: application of propofol during CPB

Delivery of isoflurane was discontinued approximately $10 \mathrm{~min}$ prior to aortic cross-clamp. Propofol was then applied as a $1.0 \mathrm{mg} \cdot \mathrm{kg}^{-1}$ bolus followed by a continuous infusion of $50(n=8), 100(n=9)$, or $150 \mu \mathrm{g} \cdot \mathrm{kg}^{-1}$. $\min ^{-1}(n=7)$ in Part One, or $120 \mu \mathrm{g} \cdot \mathrm{kg}^{-1} \cdot \mathrm{min}^{-1}$ $(n=30)$ in Part Two, until 15 min after release of the aortic cross-clamp (reperfusion).

\section{Measurement of propofol concentration}

Four millilitres of whole blood was sampled from the central venous line $15 \mathrm{~min}$ after reperfusion and stored at $-80^{\circ} \mathrm{C}$ for subsequent quantitative propofol analysis by capillary electrophoresis. ${ }^{32}$

\section{Hemodynamic data collection}

Intraoperative central venous pressure (CVP) and mean pulmonary catheter wedge pressure (PCWP) were maintained to within $\pm 20 \%$ of baseline values by volume transfusion from the CPB reservoir. Transesophageal echocardiography was employed during the perioperative period to facilitate volume loading and to rule out cardiac tamponade and pneumo- or hemothorax as possible causes of cardiac depression. Intraoperative cardiac function (CI, SVRI, and LVSWI) was measured and derived at three timepoints: pre-CPB, post-CPB emergence, and just prior to admission to the intensive care unit (pre-ICU).

Inotropic and vasoactive drug protocol

Intraoperative hemodynamic management included the use of phenylephrine $\left(1-2 \mu \mathrm{g} \cdot \mathrm{kg}^{-1} \mathrm{prn}\right)$ for blood pressure below 85 systolic or for mean arterial pressure below $50 \mathrm{mmHg}$. Blood pressure greater than $140 \mathrm{mmHg}$ systolic or mean arterial pressure above $80 \mathrm{mmHg}$ were treated by deepening anesthesia using fentanyl $\left(1-2 \mu \mathrm{g} \cdot \mathrm{kg}^{-1}\right)$ followed by the vasodilator of choice prn at the discretion of the attending anesthesiologist. If pre-CPB heart rate was above 85 beats $\cdot \min ^{-1}$ and if adequate anesthesia and analgesia was felt to have been achieved, patients were treated with metoprolol iv prn.

Systolic blood pressure below $90 \mathrm{mmHg}$ and/or a CI below $2.2 \mathrm{~L} \cdot \min ^{-1} \cdot \mathrm{m}^{-2}$, despite a PCWP range of 
Table 1 Suggested dose regimen for attending anesthesiologist

SVR systemic vascular resistance, $M P A P$ mean pulmonary arterial pressure, $N T G$ nitroglycerine

\begin{tabular}{lll}
\hline Inotrope & Starting dose & Dose range \\
\hline Epinephrine & $0.5-2 \mu \mathrm{g} \cdot \mathrm{min}^{-1}$ & $0-8 \mu \mathrm{g} \cdot \mathrm{min}^{-1}$ \\
Milrinone & $0.125-0.25 \mu \mathrm{g} \cdot \mathrm{kg}^{-1} \cdot \mathrm{min}^{-1}$ & $0-0.75 \mu \mathrm{g} \cdot \mathrm{kg}^{-1} \cdot \mathrm{min}^{-1}$ \\
Dobutamine & $3.5-7.5 \mu \mathrm{g} \cdot \mathrm{kg}^{-1} \cdot \mathrm{min}^{-1}$ & $0-10 \mu \mathrm{g} \cdot \mathrm{kg}^{-1} \cdot \mathrm{min}^{-1}$ \\
$\quad 1.5-3.5 \mu \mathrm{g} \cdot \mathrm{kg}^{-1} \cdot \mathrm{min}^{-1}$ & $0-10 \mu \mathrm{g} \cdot \mathrm{kg}^{-1} \cdot \mathrm{min}^{-1}$ \\
$\quad \mathrm{SVR}<600$ & & \\
$\quad$ & $2-4 \mu \mathrm{g} \cdot \mathrm{min}^{-1}$ & $0-8 \mu \mathrm{g} \cdot \mathrm{min}^{-1}$ \\
$\quad$ Levophed & & \\
$\quad$ Milrinone & $0.125-0.75 \mu \mathrm{g} \cdot \mathrm{kg}^{-1} \cdot \mathrm{min}^{-1}$ & \\
$\mathrm{mPAP}>25$ & & \\
$\quad \mathrm{NTG}$ and/or milrinone & $0.125-0.75 \mu \mathrm{g} \cdot \mathrm{kg}^{-1} \cdot \mathrm{min}^{-1}$ & \\
\hline
\end{tabular}

$12-15 \mathrm{mmHg}$ at the time of separation from $\mathrm{CPB}$, were treated with dopamine or dobutamine $\left(>4 \mu \mathrm{g} \cdot \mathrm{kg}^{-1} \cdot \mathrm{min}^{-1}\right)$, epinephrine or norepinephrine $\left(>0.04 \mu \mathrm{g} \cdot \mathrm{kg}^{-1} \cdot \mathrm{min}^{-1}\right)$, alone or in combination with milrinone $(0.25$ to $0.75 \mu \mathrm{g}$. $\left.\mathrm{kg}^{-1} \cdot \min ^{-1}\right)$ at the discretion of the attending anesthesiologist. Inotropic support, as described in Table 1, exceeding $30 \mathrm{~min}$ in duration was considered clinically significant.

Sample size and statistical analysis

Based on two of our previous studies, ${ }^{12,29}$ we anticipated a one-sided difference in whole-blood propofol concentrations of $2.2 \mu \mathrm{g} \cdot \mathrm{mL}^{-1}$ between doses in Study 1, with a standard deviation of $1.4 \mu \mathrm{g} \cdot \mathrm{mL}^{-1}$. The type 1 error rate was set at $\alpha=0.05$ and the power at 0.9. Accordingly, we determined a minimum sample size of seven patients per group. At the midpoint of PRO-TECT II, 72 patients had been randomized, 30 of those to the propofol treatment arm. This comprised the sample size available for analysis for Study 2; no formal sample-size calculation was performed.

All data are reported and presented as mean (SD) except for predicted values and constant of proportionality, which are described using 95\% confidence intervals. Hemodynamic parameters from Part 1 were analyzed using a twoway repeated-measures analysis of variance. Bonferroni/ Dunn post-tests for pair-wise comparisons of averages for doses across time were performed when the variance of the dose-time interaction reached a significance level of $P \leq 0.05$. Hemodynamic parameters from Part 2 are presented descriptively. All analyses were performed using GraphPad Prism ${ }^{\circledR}$ 4.0c software (San Diego, CA, USA).

\section{Results}

Patient and operative characteristics

Patient and operative characteristics according to experimental group are described in Table 2. Insufficient anesthesia, as evidenced clinically by elevated mean arterial pressure (exceeding $80 \mathrm{mmHg}$ ) and low mixed venous oxygenation (less than 65\%) on CPB, was suspected by the attending anesthesiologist in three patients receiving $50 \mu \mathrm{g} \cdot \mathrm{kg}^{-1} \cdot \mathrm{min}^{-1}$ of propofol during CPB. These patients received supplemental isoflurane. Two patients receiving $150 \mu \mathrm{g} \cdot \mathrm{kg}^{-1} \cdot \min ^{-1}$ and one receiving 100 $\mu \mathrm{g} \cdot \mathrm{kg}^{-1} \cdot \min ^{-1}$ were described as clinically unstable at separation from CPB. They required two or more inotropes, alone or in combination with norepinephrine, for hemodynamic stabilization prior to transfer to the intensive care unit (ICU).

Propofol concentrations in whole blood

\section{Part one}

The whole blood concentrations in patients treated with 50, 100 , and $150 \mu \mathrm{g} \cdot \mathrm{kg}^{-1} \cdot \mathrm{min}^{-1}$ of propofol were 2.10 (1.20), 2.96 (1.87), and 14.28 (4.79) $\mu \mathrm{g} \cdot \mathrm{mL}^{-1}$, respectively (Fig. 1). The empirical line of best fit for the relationship between propofol concentrations and infusion rates was determined using non-linear curve fitting. According to an Akaike's Information Criteria comparison, an exponential growth non-linear model was preferred over the alternative power series model. The equation is described mathematically by $y=a \cdot e^{K x}$, where $y$ represents the achieved whole-blood concentration, $x$ represents the infusion rate, and $a(0.215 ; 95 \% \mathrm{CI}=-0.088$ to 0.519$)$ and $K$ $(0.0279 ; 95 \% \mathrm{CI}=0.0181$ to 0.0376$)$ are constants of proportionality. The line had a coefficient of determination of $r^{2}=0.781$ and predicted that $113 \mu \mathrm{g} \cdot \mathrm{kg}^{-1} \cdot \min ^{-1}$ was required to achieve a mean concentration of $5 \mu \mathrm{g} \cdot \mathrm{mL}^{-1}$.

\section{Part two}

There were four study protocol violations; two patients received propofol $2.0 \mathrm{mg} \cdot \mathrm{kg}^{-1}$ bolus (propofol concentrations: $\left.10.6,11.0 \mu \mathrm{g} \cdot \mathrm{mL}^{-1}\right)$; two additional patients 
Table 2 Patient demographic and perioperative characteristics

\begin{tabular}{|c|c|c|c|c|}
\hline & \multicolumn{4}{|l|}{ Experimental group } \\
\hline & $50 \mu \mathrm{g} \cdot \mathrm{kg}^{-1} \cdot \min ^{-1}$ & $100 \mu \mathrm{g} \cdot \mathrm{kg}^{-1} \cdot \min ^{-1}$ & $150 \mu \mathrm{g} \cdot \mathrm{kg}^{-1} \cdot \min ^{-1}$ & $120 \mu \mathrm{g} \cdot \mathrm{kg}^{-1} \cdot \min ^{-1}$ \\
\hline$N$ & 8 & 9 & 7 & 30 \\
\hline Age (yr) & $59 \pm 7$ & $70 \pm 4$ & $62 \pm 10$ & $63 \pm 8$ \\
\hline Weight (kg) & $71.0 \pm 17.0$ & $76.9 \pm 12.9$ & $77.8 \pm 16.4$ & $89.4 \pm 13.9$ \\
\hline Height (cm) & $162.5 \pm 8.5$ & $165.7 \pm 7.3$ & $166.4 \pm 9.8$ & $173.1 \pm 7.2$ \\
\hline $\operatorname{BSA}\left(\mathrm{m}^{2}\right)$ & $1.78 \pm 0.23$ & $1.88 \pm 0.19$ & $1.86 \pm 0.24$ & $2.03 \pm 0.17$ \\
\hline Gender (m/f) & $4: 4$ & $7: 2$ & $4: 3$ & $29: 1$ \\
\hline LVEF (\%) & $50 \pm 17$ & $45 \pm 13$ & $51 \pm 9$ & $50 \pm 14$ \\
\hline $\mathrm{ACC}(\min )$ & $65 \pm 29$ & $101 \pm 39$ & $73 \pm 20$ & $89 \pm 28$ \\
\hline $\mathrm{CPB}$ (min) & $89 \pm 35$ & $140 \pm 59$ & $140 \pm 59$ & $119 \pm 35$ \\
\hline
\end{tabular}

Data are expressed as mean \pm standard deviation or patient numbers

$B S A$ body surface area, $L V E F$ left ventricular ejection fraction, $A C C$ aortic cross-clamp interval, $C B P$ cardiopulmonary bypass interval

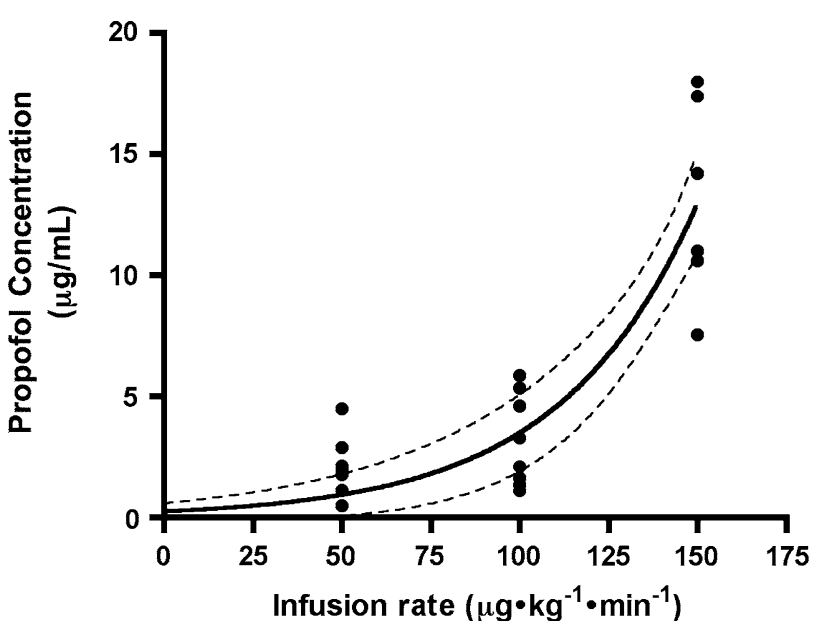

Fig. 1 Propofol concentrations in whole blood at reperfusion during aortocoronary bypass grafting with cardiopulmonary bypass in 24 patients receiving one of three infusion rates; 50,100 , or 150 $\mu \mathrm{g} \cdot \mathrm{kg}^{-1} \cdot \mathrm{min}^{-1}$. The solid line represents the empirical line of best fit $\left(r^{2}=0.781\right)$; the dotted line represents its $95 \%$ confidence interval. All concentrations were determined using capillary electrophoresis from $400 \mu \mathrm{L}$ of whole blood sampled 15 min post-reperfusion during cardiopulmonary bypass received no loading dose (propofol concentrations: 2.6, $\left.2.6 \mu \mathrm{g} \cdot \mathrm{mL}^{-1}\right)$. Three cases had operative aortic crossclamp intervals below $60 \mathrm{~min}$ (propofol concentrations: $2.4,4.0$, and $6.5 \mu \mathrm{g} \cdot \mathrm{mL}^{-1}$ ), thus intraoperatively violating study inclusion criteria. These seven patients were excluded from subsequent analysis.

The whole-blood propofol concentration from the remaining 23 patients was $5.39 \pm 1.45 \mu \mathrm{g} \cdot \mathrm{mL}^{-1}$ with a range of 2.60 to $7.54 \mu \mathrm{g} \cdot \mathrm{mL}^{-1}$. The 25,50 , and $75 \%$ quartiles were $4.36,5.63$, and $6.34 \mu \mathrm{g} \cdot \mathrm{mL}^{-1}$, respectively.

Propofol concentrations were $4.45 \mu \mathrm{g} \cdot \mathrm{mL}^{-1}(25 \mathrm{mM})$ or higher in $18 / 23$ patients $(78 \%)$ and were above $5 \mu \mathrm{g} \cdot \mathrm{mL}^{-1}$ in $15 / 23$ patients $(65 \%)$. In this series, propofol concentrations showed no apparent correlation with patient age, weight, body surface area, or aortic crossclamp duration (Fig. 2).

Intraoperative hemodynamic function

Figure 3 depicts intraoperative profiles for CI, SVRI, and LVSWI in patients receiving 50,100, and $150 \mu \mathrm{g} \cdot \mathrm{kg}^{-1}$. $\min ^{-1}$ propofol infusions alongside those from patients
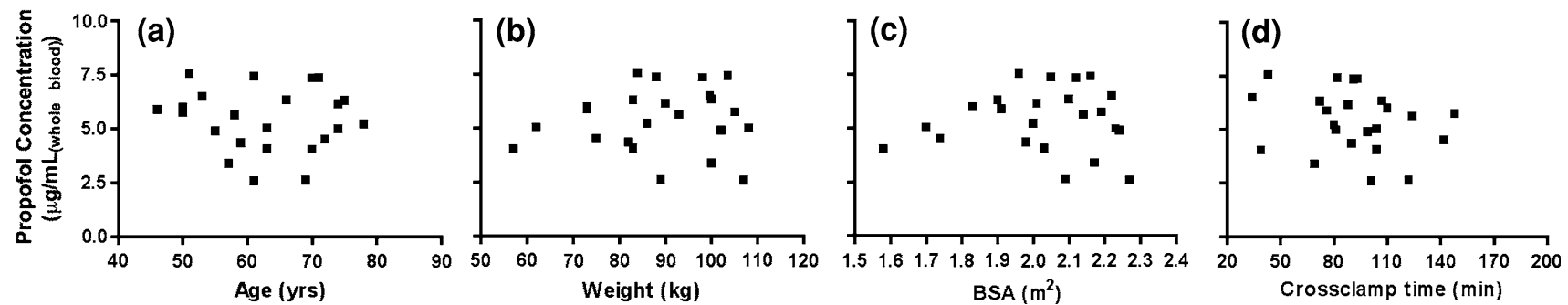

Fig. 2 Scatter plots of propofol concentration and $\mathbf{a}$ age, $\mathbf{b}$ weight, $\mathbf{c}$ body surface area, and $\mathbf{d}$ cross-clamp times for 23 patients receiving $120 \mu \mathrm{g} \cdot \mathrm{kg}^{-1} \cdot \mathrm{min}^{-1}$ of propofol during cardiopulmonary bypass 
Fig. 3 Intraoperative profiles of cardiac index $(\mathbf{a}, \mathbf{b})$, systemic vascular resistance index $(\mathbf{c}, \mathbf{d})$, and left ventricular stroke work index $(\mathbf{e}, \mathbf{f})$. Left panels $(\mathbf{a}, \mathbf{c}, \mathbf{e})$ show profiles from patients receiving one of three propofol infusion rates $(50,100$, and $\left.150 \mu \mathrm{g} \cdot \mathrm{kg}^{-1} \cdot \min ^{-1} ; n=24\right)$ during cardiopulmonary bypass. Right panels $(\mathbf{b}, \mathbf{d}, \mathbf{f})$ show profiles from patients randomized to receive $120 \mu \mathrm{g} \cdot \mathrm{kg}^{-1} \cdot \mathrm{min}^{-1}$ of propofol $(n=23)$ during cardiopulmonary bypass. Data for each treatment group are presented as the mean and standard deviation
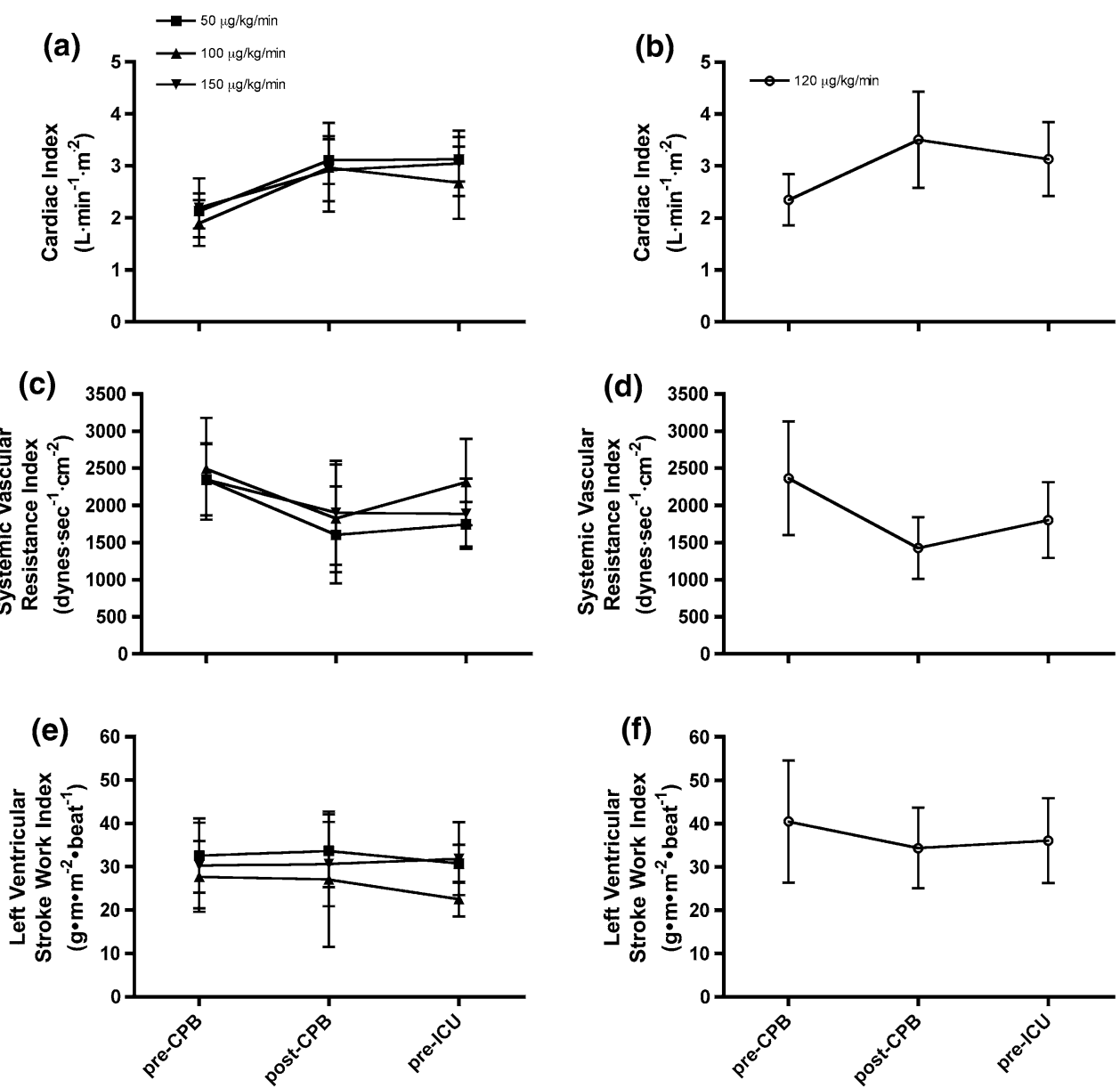

receiving $120 \mu \mathrm{g} \cdot \mathrm{kg}^{-1} \cdot \mathrm{min}^{-1}$ infusions. We did not detect significant variance in the dose-time interaction for any hemodynamic parameters (Fig. 3a, c, and e).

The hemodynamic variables presented in Fig. 3 were similar for the patients in Study 1 and Study 2.

\section{Discussion}

The current study describes conditions under which laboratory-based propofol-mediated cardioprotection was translated to an experimental clinical maneuver. In order to minimize alterations to the operative procedure and to facilitate clinical investigation, the method employed a loading bolus followed by constant infusion focused to the CPB interval. The primary research question relates to whether cardioprotective concentrations could be reliably achieved in vivo without undue risk of cardiac depression. Following are the principal findings of this study: (1) The constant infusion rate predicted to achieve a mean concentration of $5 \mu \mathrm{g} \cdot \mathrm{mL}^{-1}$ was $113 \mu \mathrm{g} \cdot \mathrm{kg}^{-1} \cdot \mathrm{min}^{-1}$; (2) The propofol concentration achieved with the nearest practical rate of $120 \mu \mathrm{g} \cdot \mathrm{kg}^{-1} \cdot \min ^{-1}$ was 5.39 $\left(1.45 \mu \mathrm{g} \cdot \mathrm{mL}^{-1}\right)$ with quartiles of $25 \%=4.36 \mu \mathrm{g}$.
$\mathrm{mL}^{-1} ; \quad 50 \%=5.63 \mu \mathrm{g} \cdot \mathrm{mL}^{-1} ; \quad$ and $75 \%=6.34 \mu \mathrm{g}$. $\mathrm{mL}^{-1}$. At this infusion rate, our model predicted a concentration of $6.10(1.76) \mu \mathrm{g} \cdot \mathrm{mL}^{-1}$; (3) Patient age, weight, body surface area, or aortic cross-clamp duration were not found to influence propofol concentration at reperfusion; (4) There was no evidence of depressed left ventricular function at emergence from $\mathrm{CPB}$ in patients receiving $120 \mu \mathrm{g} \cdot \mathrm{kg}^{-1} \cdot \mathrm{min}^{-1}$ propofol infusions during CPB.

The dosing groups in Part 1 of our study were partly modelled after a pharmacokinetic study that Gepts et al. conducted in a nonsurgical setting. ${ }^{33}$ The mathematical model we used represents an empirical means to fit our data in order to predict the infusion rate most likely to produce a given propofol concentration under similar operative and anesthetic conditions. As a result, a $1 \mathrm{mg} \cdot \mathrm{kg}^{-1}$ propofol bolus followed by a $120 \mu \mathrm{g} \cdot \mathrm{kg}^{-1} \cdot \mathrm{min}^{-1}$ continuous infusion was chosen for our PRO-TECT II protocol. Given its primary importance to tissue injury and repair, our sampling coincides with the early stage of reperfusion.

The method of drug application in our study produced a wide range of blood concentrations for a given infusion rate. This variability appears to be in line with that of several other studies where propofol concentrations were 
measured under similar operative conditions. ${ }^{27,34-37}$ It is clear that steady state conditions were not achieved, but it is also clear that steady state conditions for propofol cannot reasonably be anticipated within the context of cardiac surgery. We suggest that a significant reduction in the variance of propofol concentrations in the absence of steady state conditions will require monitoring of the concentration achieved during the course of surgery. By extension, drug level monitoring may be required to appropriately evaluate the role of propofol in cardioprotection, and its absence in experimental clinical studies makes interpretation of findings difficult.

We are satisfied that the experimental clinical maneuver derived in this study is capable of producing a propofol concentration associated with laboratory-based cardioprotection. Indeed, the effect of increased propofol dosing to achieve the therapeutic concentration range associated with laboratory-based propofol mediated cardioprotection (25$50 \mathrm{mM}$ ) was achieved clinically in $78 \%$ of patients in our study. The highest level we measured was approximately $7.5 \mu \mathrm{g} \cdot \mathrm{mL}^{-1}(45 \mathrm{mM})$, as seen in $17 \%$ of cases. This concentration is clinically and experimentally relevant, given these levels have been previously associated with the range expected to inhibit both lipid peroxidation ${ }^{38}$ and mitochondrial permeability transition. ${ }^{16}$ The absence of high drug levels among patients in Study 2 suggests that a large dose of propofol applied during CPB had no detrimental effect on early post-bypass functional recovery relative to lower infusion rates. This contrasts with reports where total intravenous anesthesia with propofol and remifentanil was used for cardiac surgery. ${ }^{17}$

Consistent with our definition of cardiac depression, we did not observe a decrease in CI across dosing groups upon emergence from CPB. This pattern was associated with a decrease in SVRI and the maintenance of LVSWI (Fig. 3). By extension, elevated doses of propofol during cardioplegic arrest do not appear to increase the risk of cardiac instability on emergence from CPB. The benefit of this method with respect to clinical outcomes and cardioprotection cannot be extrapolated in the current study and remains to be determined.

Patient characteristics of age, disease state, and weight have been identified as significant covariates that influence propofol pharmacokinetics. ${ }^{33,39}$ Their effect on data-spread effects is likely to be amplified in non-steady-state conditions. We did not find any systematic influence of these parameters on propofol concentrations at reperfusion (Fig. 2), suggesting that non-steady-state conditions and variability in total infused drug volume have a larger influence.

We used capillary electrophoresis to quantitatively analyze propofol in whole blood. ${ }^{32}$ The separation is completed in less than $8 \mathrm{~min}$, but the length of the preparative step still precludes its use for point-of-care target-achieved type dosing. Quantitative analysis that provides target-achieved drug infusion would likely facilitate perioperative care of high-risk patients. Technologies that enable target-achieved dosing could then be adopted for routine use in studies designed to determine clinical outcomes.

There are limitations to the present study. First, propofol concentrations were only measured in central venous blood collected at one point in time, which limits any pharmacokinetic interpretations of the data. Central venous sampling was used for quantitative propofol analysis. Siteeffect studies have confirmed that venous sampling is equally representative of arterial drug concentrations, provided the infusion interval prior to sampling is longer than 20 min. ${ }^{39-44}$ Second, the mathematical model described in this study is inherently susceptible to changes in the anesthetic maneuver and is incapable of predicting propofol concentrations in routine clinical practice or beyond the infusion rates used in our study. In the absence of controls that omit propofol anesthesia, we are unable to attribute either the magnitude or the pattern of hemodynamic changes to the administration of propofol. The volume of propofol delivered in our study prior to sampling is entirely dependent on patient weight and cross-clamp interval. Cross-clamp intervals are neither consistent between surgical cases nor sufficient to establish near steady-state pharmacokinetic conditions. ${ }^{33,45}$ For these reasons, our line of best fit has no pharmacokinetic basis; its constants do not represent any physiological parameters, and there is no basis for the apparent log-linear relationship between the infusion rate and the concentration that its equation suggests. The current study focused on the intraoperative interval. Any patterns of hemodynamic performance are not known to extend to the postoperative period. Finally, our hemodynamic findings are not known to apply to patients with severe ventricular dysfunction and profoundly low cardiac output, or to patients treated with drugs used to treat low cardiac output, such as milrinone.

The current study introduces an experimental clinical maneuver focused to the CPB interval that is capable of yielding an elevated propofol concentration at reperfusion. In summary, the administration of a $1 \mathrm{mg} \cdot \mathrm{kg}^{-1}$ bolus propofol dose followed by a $120 \mu \mathrm{g} \cdot \mathrm{kg}^{-1} \cdot \mathrm{min}^{-1}$ continuous infusion during $\mathrm{CPB}$ produced relevant cardioprotective drug concentrations in whole blood at reperfusion. These concentrations were associated with an increase in CI at emergence from CPB in the absence of additional inotropic support. The achieved drug concentrations have previously been associated with enhanced red cell and tissue antioxidant capacity in vitro and in vivo, enhanced recovery from experimental ischemia reperfusion, and reduced endothelial and cardiomyoblast 
apoptosis. Failure to prevent cardiac injury with conventional propofol doses could be explained by inadequate concentrations and timing of administration. It remains to be determined if achieving a target concentration of $5 \mu \mathrm{g} \cdot \mathrm{mL}^{-1}$ will improve clinical outcomes (morbidity and mortality) in high-risk patient populations undergoing cardiac surgery.

Funding sources Core funding for this project was provided through the 2005-2006 International Anesthesia Research Society (IARS) Clinical Scholar Research Award and the 2005 Canadian Anesthesiologists' Society (CAS) Dr. Earl Wynands Research Award. Additional support was provided by the Canadian Institutes of Health Research Operating Grant \#82757 and a discovery grant from the Natural Sciences and Engineering Research Council of Canada. DMA is the recipient of the 2005-2006 IARS Clinical Scholar Research Award and the 2005 CAS Dr. Earl Wynands Research Award in Cardiovascular Anesthesia. KR and YH are recipients of Canada Graduate Scholarships from the Canadian Institutes of Health Research.

Competing interests None declared.

\section{References}

1. Piper HM, Meuter K, Schafer C. Cellular mechanisms of ischemia-reperfusion injury. Ann Thorac Surg 2003; 75: S644-8.

2. De Hert SG, Cromheecke S, ten Broecke PW, et al. Effects of propofol, desflurane, and sevoflurane on recovery of myocardial function after coronary surgery in elderly high-risk patients. Anesthesiology 2003; 99: 314-23.

3. Symons JA, Myles PS. Myocardial protection with volatile anaesthetic agents during coronary artery bypass surgery: a metaanalysis. Br J Anaesth 2006; 97: 127-36.

4. Yu CH, Beattie WS. The effects of volatile anesthetics on cardiac ischemic complications and mortality in CABG: a meta-analysis. Can J Anesth 2006; 53: 906-18.

5. Tritapepe L, Landoni G, Guarracino F, et al. Cardiac protection by volatile anaesthetics: a multicentre randomized controlled study in patients undergoing coronary artery bypass grafting with cardiopulmonary bypass. Eur J Anaesthesiol 2007; 24: 323-31.

6. Piriou V, Mantz J, Goldfarb G, et al. Sevoflurane preconditioning at 1 MAC only provides limited protection in patients undergoing coronary artery bypass surgery: a randomized bi-centre trial. Br J Anaesth 2007; 99: 624-31.

7. Wang $X$, Jarvinen $O$, Kuukasjarvi $P$, et al. Isoflurane produces only minor preconditioning in coronary artery bypass grafting. Scand Cardiovasc J 2004; 38: 287-92.

8. Tanaka K, Kehl F, Gu W, et al. Isoflurane-induced preconditioning is attenuated by diabetes. Am J Physiol Heart Circ Physiol 2002; 282: H2018-23.

9. Riess ML, Stowe DF, Warltier DC. Cardiac pharmacological preconditioning with volatile anesthetics: from bench to bedside? Am J Physiol Heart Circ Physiol 2004; 286: H1603-7.

10. Kevin LG, Katz P, Camara AK, Novalija E, Riess ML, Stowe DF. Anesthetic preconditioning: effects on latency to ischemic injury in isolated hearts. Anesthesiology 2003; 99: 385-91.

11. Gross GJ, Auchampach JA. Reperfusion injury: does it exist? J Mol Cell Cardiol 2007; 42: 12-8.

12. Ansley DM, Lee J, Godin DV, Garnett ME, Qayumi AK. Propofol enhances red cell antioxidant capacity in swine and humans. Can J Anaesth 1998; 45: 233-9.
13. Kim HS, Chang WC, Hwang KC, Choi IG, Park WK. Effect of propofol on calcium homeostasis in hypoxia-reoxygenated neonatal rat cardiomyocytes. Eur J Pharmacol 2008; 594: 139-45.

14. Wang B, Luo T, Chen D, Ansley DM. Propofol reduces apoptosis and up-regulates endothelial nitric oxide synthase protein expression in hydrogen peroxide-stimulated human umbilical vein endothelial cells. Anesth Analg 2007; 105: 1027-33.

15. Sztark F, Ichas F, Ouhabi R, Dabadie P, Mazat JP. Effects of the anaesthetic propofol on the calcium-induced permeability transition of rat heart mitochondria: direct pore inhibition and shift of the gating potential. FEBS Lett 1995; 368: 101-4.

16. Javadov SA, Lim KH, Kerr PM, Suleiman MS, Angelini GD, Halestrap AP. Protection of hearts from reperfusion injury by propofol is associated with inhibition of the mitochondrial permeability transition. Cardiovasc Res 2000; 45: 360-9.

17. De Hert SG, ten Broecke PW, Mertens E, et al. Sevoflurane but not propofol preserves myocardial function in coronary surgery patients. Anesthesiology 2002; 97: 42-9.

18. Karashima $Y$, Oike M, Takahashi S, Ito $Y$. Propofol prevents endothelial dysfunction induced by glucose overload. $\mathrm{Br} \mathrm{J}$ Pharmacol 2002; 137: 683-91.

19. Ko SH, Yu CW, Lee SK, et al. Propofol attenuates ischemiareperfusion injury in the isolated rat heart. Anesth Analg 1997; 85: 719-24.

20. Xia Z, Godin DV, Ansley DM. Application of high-dose propofol during ischemia improves postischemic function of rat hearts: effects on tissue antioxidant capacity. Can J Physiol Pharmacol 2004; 82: 919-26.

21. Xia Z, Godin DV, Chang TK, Ansley DM. Dose-dependent protection of cardiac function by propofol during ischemia and early reperfusion in rats: effects on 15-F2t-isoprostane formation. Can J Physiol Pharmacol 2003; 81: 14-21.

22. Kokita N, Hara A, Abiko Y, Arakawa J, Hashizume H, Namiki A. Propofol improves functional and metabolic recovery in ischemic reperfused isolated rat hearts. Anesth Analg 1998; 86: 252-8.

23. Mathur S, Farhangkhgoee P, Karmazyn M. Cardioprotective effects of propofol and sevoflurane in ischemic and reperfused rat hearts: role of K(ATP) channels and interaction with the sodiumhydrogen exchange inhibitor HOE 642 (cariporide). Anesthesiology 1999; 91: 1349-60.

24. Lim KH, Halestrap AP, Angelini GD, Suleiman MS. Propofol is cardioprotective in a clinically relevant model of normothermic blood cardioplegic arrest and cardiopulmonary bypass. Exp Biol Med (Maywood) 2005; 230: 413-20.

25. Kamada N, Kanaya N, Hirata N, Kimura S, Namiki A. Cardioprotective effects of propofol in isolated ischemia-reperfused guinea pig hearts: role of KATP channels and GSK-3beta. Can J Anesth 2008; 55: 595-605.

26. Yoshitani K, Kawaguchi M, Takahashi M, Kitaguchi K, Furuya $H$. Plasma propofol concentration and EEG burst suppression ratio during normothermic cardiopulmonary bypass. Br J Anaesth 2003; 90: 122-6.

27. Hiraoka H, Yamamoto K, Okano N, Morita T, Goto F, Horiuchi $R$. Changes in drug plasma concentrations of an extensively bound and highly extracted drug, propofol, in response to altered plasma binding. Clin Pharmacol Ther 2004; 75: 324-30.

28. Rosen DA, Rosen KR. Elimination of drugs and toxins during cardiopulmonary bypass. J Cardiothorac Vasc Anesth 1997; 11: 337-40.

29. Ansley DM, Sun J, Visser WA, et al. High dose propofol enhances red cell antioxidant capacity during $\mathrm{CPB}$ in humans. Can $\mathrm{J}$ Anesth 1999; 46: 641-8.

30. Xia Z, Huang Z, Ansley DM. Large-dose propofol during cardiopulmonary bypass decreases biochemical markers of myocardial injury in coronary surgery patients: a comparison with isoflurane. Anesth Analg 2006; 103: 527-32. 
31. Ansley DM, Raedschelders K, Chen DD, Choi PT. Rationale, design and baseline characteristics of the PRO-TECT II study: PROpofol CardioproTECTion for Type II diabetics: a randomized, controlled trial of high-dose propofol versus isoflurane preconditioning in patients undergoing on-pump coronary artery bypass graft surgery. Contemp Clin Trials 2009; 30: 380-5.

32. Hui $Y$, Raedschelders $K$, Zhang $H$, Ansley DM, Chen DD. Quantitative analysis of propofol in whole blood using capillary electrophoresis. J Chromatogr B Analyt Technol Biomed Life Sci 2009; 877: 703-9.

33. Gepts E, Camu F, Cockshott ID, Douglas EJ. Disposition of propofol administered as constant rate intravenous infusions in humans. Anesth Analg 1987; 66: 1256-63.

34. Dawson PJ, Bjorksten AR, Blake DW, Goldblatt JC. The effects of cardiopulmonary bypass on total and unbound plasma concentrations of propofol and midazolam. J Cardiothorac Vasc Anesth 1997; 11: 556-61.

35. Hammaren E, Yli-Hankala A, Rosenberg PH, Hynynen M. Cardiopulmonary bypass-induced changes in plasma concentrations of propofol and in auditory evoked potentials. Br J Anaesth 1996; 77: $360-4$.

36. Takizawa E, Hiraoka H, Takizawa D, Goto $F$. Changes in the effect of propofol in response to altered plasma protein binding during normothermic cardiopulmonary bypass. Br J Anaesth 2006; 96: 179-85.

37. Massey NJ, Sherry KM, Oldroyd S, Peacock JE. Pharmacokinetics of an infusion of propofol during cardiac surgery. $\mathrm{Br} \mathrm{J}$ Anaesth 1990; 65: 475-9.
38. Shao H, Li J, Zhou Y, et al. Dose-dependent protective effect of propofol against mitochondrial dysfunction in ischaemic/reperfused rat heart: role of cardiolipin. Br J Pharmacol 2008; 153: 1641-9.

39. Schuttler J, Ihmsen H. Population pharmacokinetics of propofol: a multicenter study. Anesthesiology 2000; 92: 727-38.

40. Su HB, Chen TY, Cheng CF, Yang YJ, Huang JD, Tseng CC. The hypotensive effects of propofol at different sampling sites in cardiopulmonary bypass model. Acta Anaesthesiol Sin 2003; 41: 125-30.

41. Grossherr M, Hengstenberg A, Meier T, Dibbelt L, Gerlach K, Gehring $H$. Discontinuous monitoring of propofol concentrations in expired alveolar gas and in arterial and venous plasma during artificial ventilation. Anesthesiology 2006; 104: 786-90.

42. Coetzee JF, Glen JB, Wium CA, Boshoff L. Pharmacokinetic model selection for target controlled infusions of propofol. Assessment of three parameter sets. Anesthesiology 1995; 82: $1328-45$.

43. Hiraoka H, Yamamoto K, Miyoshi S, et al. Kidneys contribute to the extrahepatic clearance of propofol in humans, but not lungs and brain. Br J Clin Pharmacol 2005; 60: 176-82.

44. Major E, Aun C, Yate PM, et al. Influence of sample site on blood concentrations of ICI 35868. Br J Anaesth 1983; 55: 371-5.

45. Levitt DG, Schnider TW. Human physiologically based pharmacokinetic model for propofol. BMC Anesthesiol 2005; 5: 4. 